\title{
A VISUAL TALE OF TWO CITIES: VIDEO AS A TOOL FOR REPRESENTATION THROUGH INFORMAL LEARNING
}

\author{
U. Topcu(1); J. Taberna(2); K. Hofert(2) \\ (1)Faculty of Architecture and Design; (2)ETSAB \\ (1)Istanbul Bahçeşehir University;(2)UPC \\ umran.topcu@bahcesehir.edu.tr
}

\section{SUMMARY I ABSTRACT}

In recent years, videos have become significant aspects of learning experience. Learning now occurs in a variety of ways through different communities of practice and personal networks. This is true for learning in design arena. Architectural design education consists of theoretical and practical courses aiming at contribution to the society at social and cultural levels. With the advent of globalization another aim has become contribution to the society at international level. International workshops are held frequently between architectural schools resulting in outstanding success and sharing.

This paper is about an international workshop titled "In the Pursuit of Sinan" held in İstanbul in January 2015. Students from BAU FA\&D and UPC ETSAB were asked to create a stop motion video of the two cities they visited. Going through Sinan's works while walking around the city, in İstanbul and Edirne, Turkish and Spanish students encountered both cities with all their senses and voiced tales of two cities in stop motion video format.

Key words: Istanbul, Sinan, workshop, stop motion video 


\section{INTRODUCTION}

Developments in digital technology have opened new visions for education, which offer the students the flexibility to learn at any time and any place. As formal learning no longer comprises majority of education, architectural design education has adapted quickly to this reality. Architectural design education consists of theoretical and practical courses aiming at contribution to the development of the society at social and cultural levels besides the economic. With the advent of globalization another aim should be contribution to the society at international level. In this context, besides formal architectural education, informal studies such as workshops have a growing importance.

Workshops are held frequently between two or more number of architectural schools from different countries resulting in outstanding success and sharing. They help the student design thinking skills, learning by doing skills, creating motivation for creativity and most important of all, self-confidence in international environments.

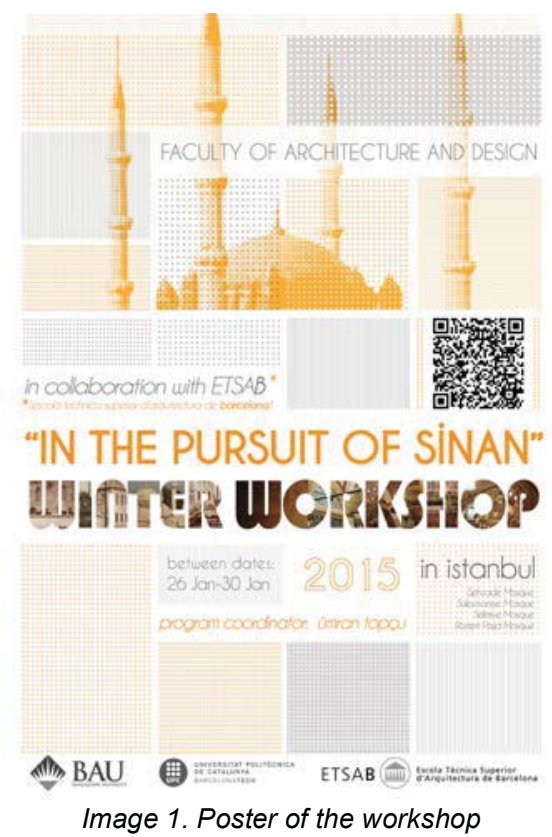

This paper is about a workshop titled "In the Pursuit of Sinan" held in İstanbul, on 26-30 January 2015, see the poster in image 1. It was held between Escola Tècnica Superior d'Arquitectura de Barcelona and BAU Faculty of Architecture and Design. Fifty-two students from both faculties worked in joint groups of six or seven members. As the assignment of the workshop, students were asked to create a stop motion video of the two cities they visited. Going through Sinan's works in İstanbul and Edirne, Spanish and Turkish students encountered both cities with all their senses and emotions. In spite of the short time, the students searched for a best learning experience, see image 2. Videos are appealing. Nowadays they can be made with low budgets, which is one of the important challenges to universities. 


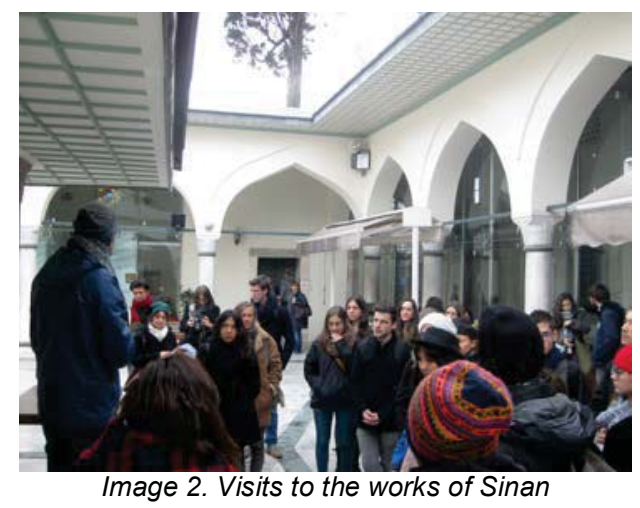

\section{VIDEO AS A TOOL FOR REPRESENTATION}

In the recent years, videos have played an important role in education. Videos help increase student engagement and facilitate learning. What is more, it is a demanding process. It requires selecting appropriate words and images, arranging them into coherent verbal and pictorial ways. This arrangement needs prior knowledge [1]. Videos have an advantage of, when done objectively, explaining in a few seconds something that needs several pages when written. This, together with the fact that students may see them whenever they can and play as many times as they need it, makes them a very powerful tool for enhancing learning efficiency [2]. Majority of the students are used to technology since they are born, so they must be provided with the necessary tools in their education process.

Video is different from other learning technologies because it offers the benefit of using the visual perception, the most powerful of all our senses. An image in motion helps the viewer to see a process and find out how things work, move and perform. According to Goodyear and Steeples [3] videos can present a clear and striking manner descriptions to articulate tacit information and knowledge hard to describe through text. See in image 3, two frames of the stop motion video "RITIM", made by one of the groups of the workshop, their work explores the relation between buildings and places, and their geometries, it is a easy way to represent through different images, a concept that should be difficult to understand through text.

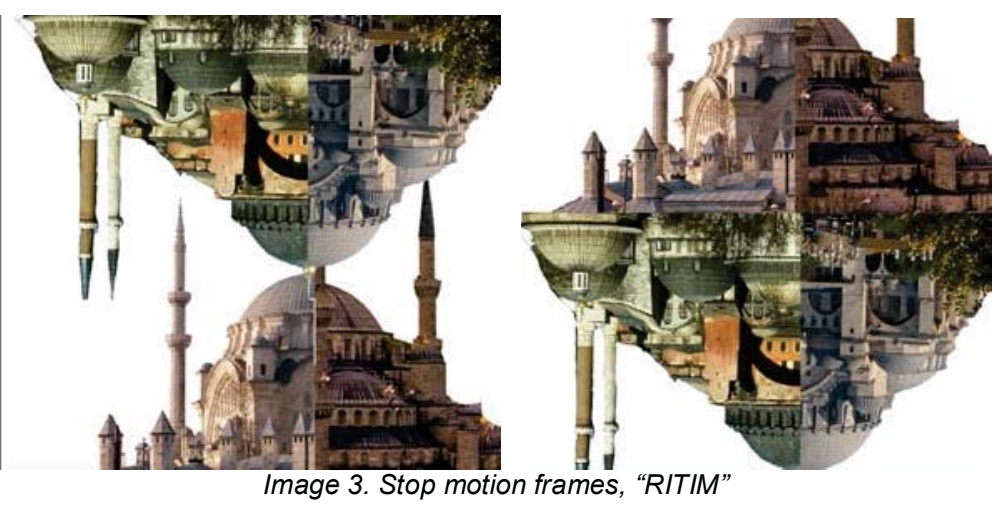

The technological development seems to be fast but still little is known how to produce and effectively use them for educational purposes. The manner in which 
students select an approach for a learning situation has many effects on performance and the learning outcomes [4].

There are various theoretical explanations, models and measures about learning styles. As an example dual coding theory can be mentioned. The theory says that there are two classes of phenomena that are handled cognitively in separate sub systems: one deals with objects while the other deals with language [5].

Presenting information is an important part of learning. Some presenters are verbalizers while some are imagers. Verbalizers are better in presenting the information in words and imagers in pictorial form [6]. So, if information is presented in both formats, the students can choose between the formats, the best for their learning. Learning preference is a function of learner's capability of information intake. Here, "intake" means what the learner finds important or worth learning.

Videos are effective means to use the auditory and the visual perception for learning. When the video presents more information than the learner can "intake", there might be a perceptual overload. We, human beings are so good at processing the appropriate amount of information at a time. The overload in watching a video can be interpreted based on two theories: cognitive load theory and cognitive theory of multimedia learning [7]. These two theories both state that human memory has a certain cognitive capacity and if it is overloaded, learning may not be optimized. According to this, in order to learn more effectively, the cognitive load should be kept optimal. Since, people's perception capacity varies from one to the other, the editorial decision for the optimal amount of information in videos for education is difficult. Sometimes it is the pace and the rhythms of the video that make the overload rather than the information. See in image 4, some frames of one of the stop motion videos made by the students "Reflect Motion", a view of the city through the reflects produced on the ground by water.

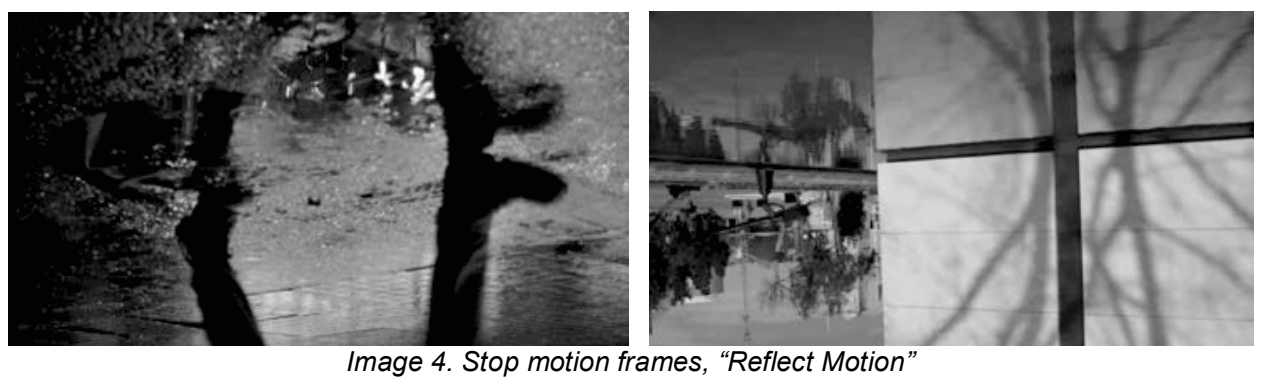

Bishop et al. [8] found that sound and music attract attention, but they do not have any effect on learning. Too much information may lead to an effect that, the necessary part of the information may be unnoticed.

\section{METHODOLOGY}

In this workshop, the students were asked to create a stop motion video of their Istanbul and Edirne experiences. They were supposed to focus on the spatial, visual and audio characteristics of both cities. The student groups produced 9 videos. The duration of the video was defined between three or four minutes. The titles of the videos were: "RITIM", "Here we go", "One city two perceptions", "Reflect Motion", "Synesthesia", "Feeling through Sinan", "Istanbul", "Light is only 
real between shadows" and "Senses experiencing Istanbul. Because they were working against time, in the final presentation the students found themselves in a position of "saying the most in 10-15 minutes using appropriate amount of verbal and image information". The oral presentation of the final stop motion video took place on the last day of the workshop.

The students that participated in the workshop didn't know each other before, because they were from two different universities and also from different levels of architectural education. So they were all asked to present themselves to the class. After this, they were given fifteen minutes for forming different groups of six or seven students. In our opinion, it was important that the students should themselves decide in which group they were going to take part. When all the groups were formed, they were asked to think about a name for their groups and also to make a drawing of combined ideas of two cities: Barcelona and Istanbul. Image 5, is an example of the drawings they made. This group decided to define the two cities through a skyline, starting with Barcelona and ending with Istanbul.

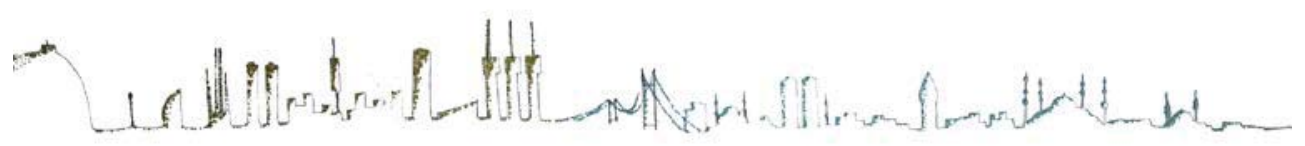

Image 5. Barcelona-Istanbul skyline

After the groups were formed, it was time to introduce the stop motion technique to the workshop students. In general, this was not a commonly used representational tool at both universities. The students were shown different examples and were informed about possibilities of new ideas for making the videos. As seen in Image 6, two of the frames for two different stop motion videos titled "One city, two perceptions" and "Sinesthesia", two different techniques of using newspaper letters and letters drawn on paper for doing the titles, were used. This happens to be very common in stop motion movies.

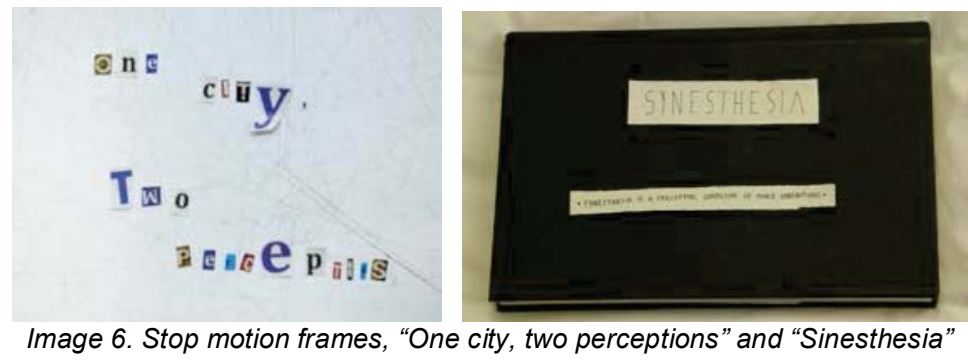

One of the important stages of doing a stop motion video is the way the story is explained, namely the storyboard. The storyboard concept was defined as a tool for creating the videos. All of the elements that took part in the movie; scene, frames, space, camera position, music, movements, characters, time, action were explained in detail. The students were given a template storyboard, as seen in Image 7, to guide them to design the story of these two cities. They had to hand this template in along with their drawings, at the final presentation of the stop motion videos, on the last day of the workshop. 


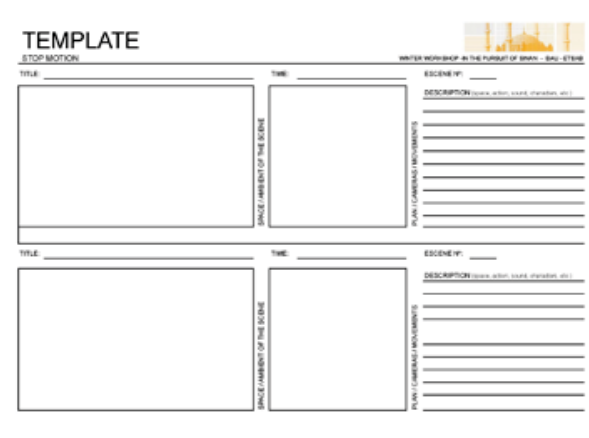

Image 7. Template storyboard

On the template, the first box was supposed to have a three-dimensional drawing including the scene with the position of the characters and their movements. In the second box they had to draw the plan of the scene with the position of the cameras and their movements around the space. And on the right side of the template they had to write the duration of the frame, the space where the action was going to take place, the music they were going to use, define the characters and explain all the relevant information for the movie.

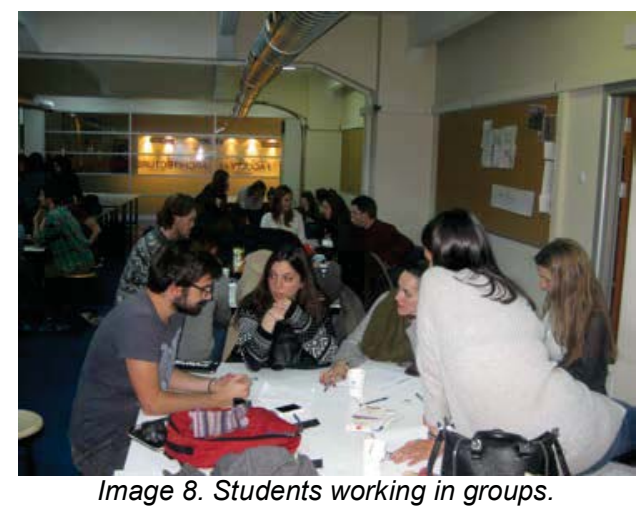

In Image 8, the students are seen working in groups in this first stage, defining the global story and doing the first sketches of their storyboard. Once they had defined the storyboard the groups could start preparing all the documentation for the stop motion video. The students had to mix different techniques of graphic representation for doing their movies. One of the main rules was the importance of introducing hand drawings in their works. They did it using notebooks and pens, but also with digital tools. In Image 9, the group with the stop motion video titled "Istanbul" used this image made by hand for starting the video. A sequence of three different frames of the evolution of this title can be seen as starting with the minarets of different mosques of the city. Finally, they are seen as being converted into the eight letters of Istanbul.

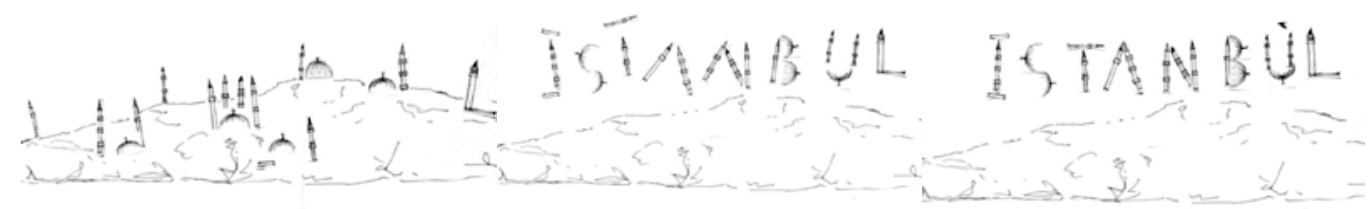

Image 9. Stop motion with the title "Istanbul" 
The students could use different technological tools for doing their stop motion video. Each group decided which program they were going to use depending on their knowledge in computer applications. The tools that the students used for the stop motion videos were "Adobe Premier", "IMovie", "Windows Movie Maker" and "PowerPoint". It was not important for the instructors which platform the students used to perform the videos, because the software used was just a tool to explain the ideas of the different groups.

All of the students were encouraged to have a sketchbook along with them during the visits of the workshop. In general, at least one or two students per group were doing sketches while visiting the places and buildings of Istanbul and Edirne (See image 10).

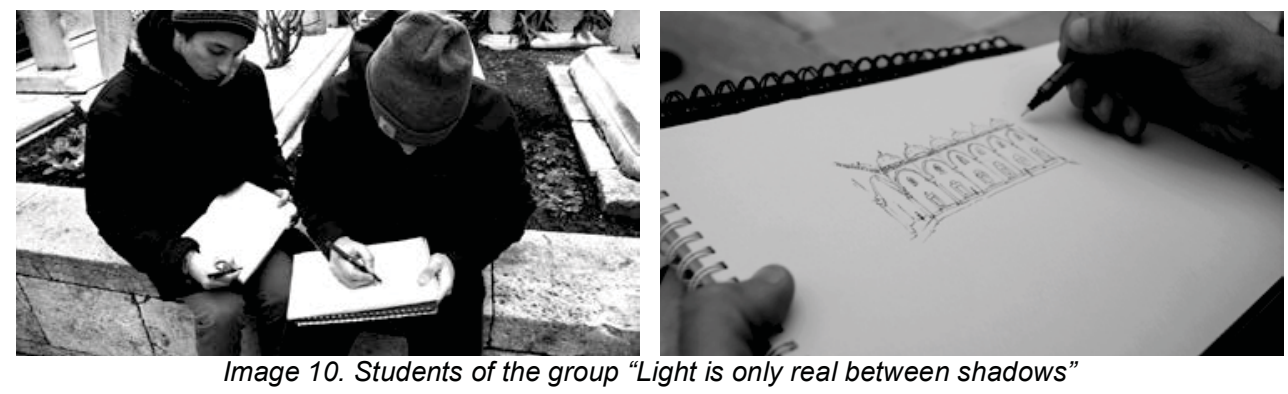

The students were asked to focus on hand drawings, because is a tool that coordinates the brain with the hand and allows to capture very quick impressions of the visited sites. As John Berger [9] said: "There are many types of drawings: ones are studies, forms of research and other projects that are sketches of masterpieces". We were interested in these drawings as forms of research, as a tool for discovering new aspects of the cities. The students were not expected to do perfectly finished drawings. We were looking for incomplete ideas that appeared on the sketches. In image 11, three different frames of the stop motion video titled "Reflect Motion" can be seen as examples. The use of different hand drawing techniques with markers, watercolours and all mixed, with the water falling on the sketch, the effect produced different experimental drawings.

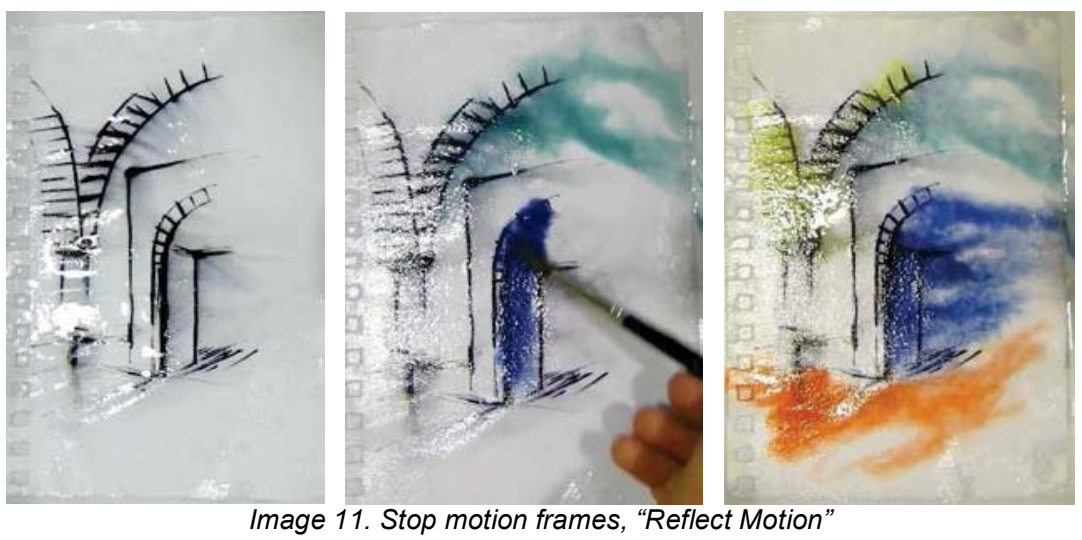

All the groups used sketches and photographs in their stop motion videos. They were asked to create a story mixing all the techniques explained in the stop motion video. As seen in image 12, an example of some of the frames of the stop motion video titled "Here we go" made during the workshop, in three frames the 
students mixed sketches with photos of themselves going through different buildings of the two cities visited, focusing mainly on mosques.
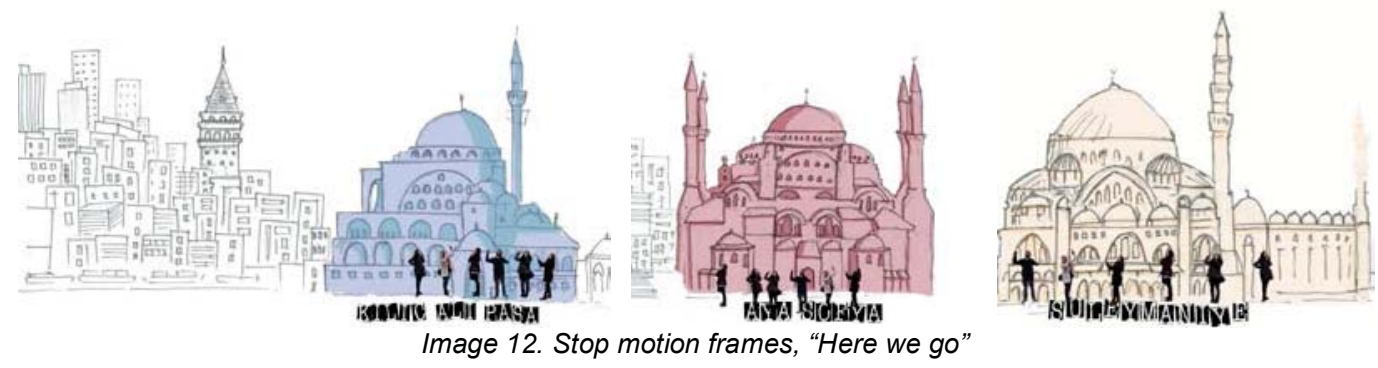

In image 13, we can see another example of mixing techniques. In this case, the group drew on some of the images of the stop motion, with the idea of defining and explaining the main important parts of the story they were explaining.

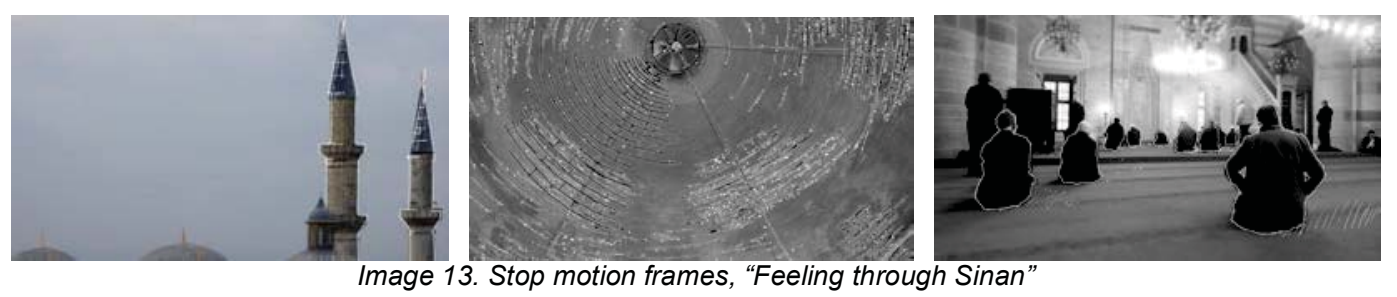

We focus on the importance of exploring, studying and analysing the cities, as Georges Perec [10] described in his book: "Our look moves around the space and gives us the illusion of relief and distance. So we built the image of space: from above and below, from left and right, from front and back, from close and a far". With the sense of vision and the sense of touch our students were able to find all the necessary information for creating their stop motion videos. In image 14 , one can move around the space as one sees it in these three frames of the stop motion "Senses, experiencing Istanbul". One can have a look at the city in three different ways: first, as a sketch with very simple lines without colour, light or textures just the main shape: second, as a black and white image, where texture and light takes relevance: and third as in the colour version, where everything gets mixed together.

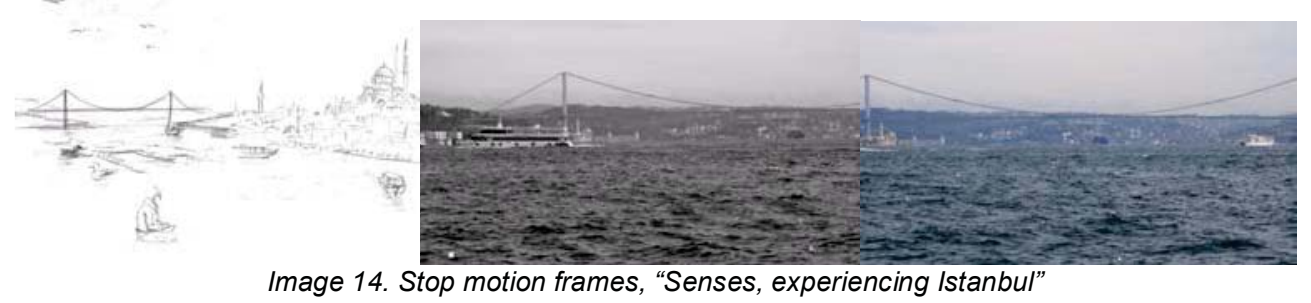

We explained the relevance of feeling with the cities. We encouraged the students not just to walk, but to live the places and buildings. As Pallasmaa [11] says "Architectural space is lived space rather than physical space, and lived space always transcends geometry and measurability". We challenged the groups for trying to find this lived space, these personal feelings they had while they were going around different places. In image 15, we have four frames of the stop motion video titled "Synesthesia". They defined their work synesthesia, as a perceptual condition of mixed sensations. They played with music, water, light 
and colours, and their hands and feet. They touched the places visited, feeling the temperature of the materials, the texture, the reflections. One cannot feel all these aspects only by using the sense of vision. It is important to give the students different tools and different ways of walking through the cities.
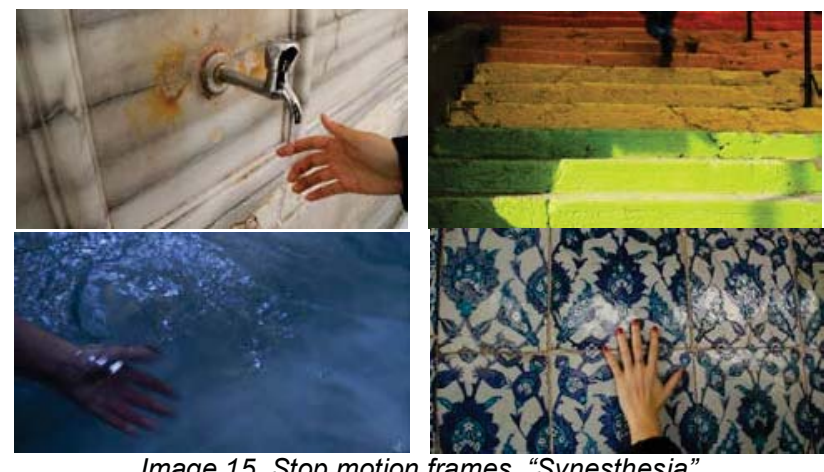

Image 15. Stop motion frames, "Synesthesia"

In image 16, there is another example of a stop motion video titled "One city, two perceptions". In this movie the students also worked with the concept of senses, making a reflection of how people with different capabilities perceive the cities. They tried to imagine the way these people feel when they go around different places that they are not prepared for. In these three frames, they showed us the process of sketching a place and deciding which lines were more important to be expressed in the drawings. They focused on the essence of the space, avoiding ornaments and decorations for better understanding the place. Finally, in the last frame of the sequence they connected this sketch with reality. Actually, our mind is perfectly able to create the real image of the lived space just through their sketches.

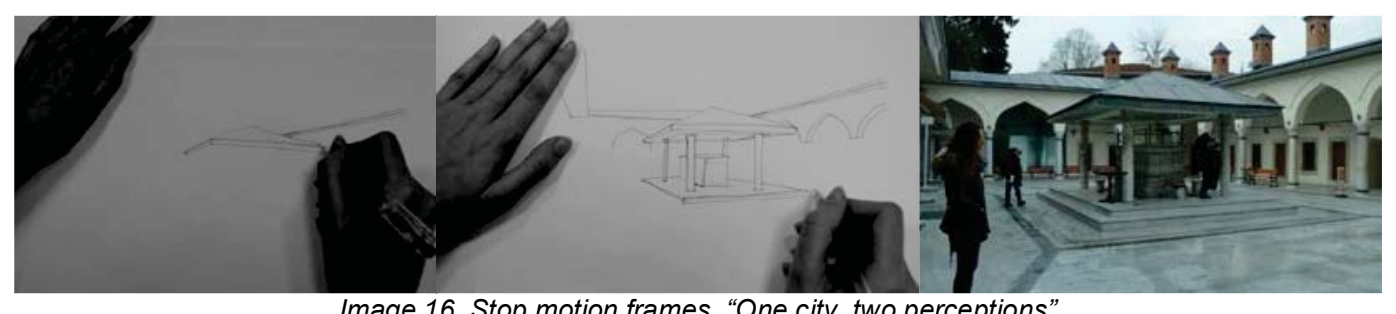

Image 16. Stop motion frames, "One city, two perceptions"

In general, all the nine videos presented on the last day of the workshop were related with the concept of senses. All of them did good research on this new way of experimenting with the city. It was a challenge for the students to work with a different tool of graphic representation of spaces, namely the stop motion videos. All of them succeeded. All the groups enjoyed thinking and imagining the best way to express their ideas through a stop motion video of a short duration, just between three to four minutes.

\section{CONCLUSION}

In recent years, videos have played an important role in education. Videos help create student engagement and facilitate learning. This is true for learning in all design arenas, as well as architectural design.

Over the last decades, technology has been reorganizing our ways of learning. With the advent of globalization, one of the aims of architectural design education 
has been contribution to the society at an international level. International workshops are held frequently between architectural schools resulting in outstanding success and sharing. Growing popularity of videos proved to be right in the case of 2015 Winter Workshop in Istanbul and Edirne. Potential benefits and challenges associated with making videos in the teaching and learning process at higher education level has been a good experience both for the students and the faculty alike.

By using the stop motion video techniques, all the groups of students have studied the two cities in different ways, so as not just looking through a camera. People do not process information about the environment the way cameras or computers do. Our processing is full of errors and our perceptions differ from one to the next. Our imperfect images are quite useful to us. The stop motion videos produced by the workshop students were a perfect indication of this.

Thinking and reflecting on the buildings and places they visited, students had a chance of experimenting lived space by using all their senses and through their sketches and mixed images shown in their stop motion videos. It was a challenge because the conditions were not the best. Budget was zero and there was not much support neither in terms of producing, designing and technology.

There seems to be no doubt that the number of higher education institutions of design will aim at making and using more videos. From now on, the pedagogical problem should be stated as: the optimum length of videos and their dependence upon subjects.

\section{BIBLIOGRAPHY}

[1] Mayer, R.E. (2005). The Cambridge handbook of multimedia learning. University of Cambridge, Cambridge, UK.

[2] Vieira, I., Lopes, A. P., Soares, F. (2014). The potential benefits of using videos in higher education. EDULEARN 14 Conference on Education and New Learning Technologies. Conference Proceedings CD. Pp.750-756, ISBN:978-84617-0557-3

[3] Goodyear, P., Steeples, C. (1998). Creating shareable representations of practice, Advance Learning Technology Journal (ALT-J), 6(3), pp.16-23

[4] Cassidy, S. (2004). Learning Styles: An overview of theories, models and measures. Educational Psychology 24(4), pp.419-444

[5] Paivio, A. (1986). Mental representations: A dual coding approach. Oxford, England: Oxford University Press.

[6] Mc Loughlin, C. (1999). The implications of the research literature on learning styles for the design of instructional material. Australian Journal of Educational Technology 15(3), pp.222-241

[7] Moreno, R., \& Mayer, R.E. (1999). Cognitive principles of multimedia learning: The role of modality and contiguity. Journal of Educational Psychology 99, pp.358-368 
[8] Bishop, M. J., Amankwatia, T. B., Cates, W. M. (2008). Sound's use in instructional software to enhance learning: a theory-to-practice content analysis. Educational Technology Research and Development 56, pp.467-486

[9] Berger, J. (2007). Berger on Drawing. Occasional Press.

[10] Perec, G. (1974). Species of spaces and other pieces. Penguin Classics.

[11] Pallasmaa, J. (2012). The eyes of the skin: Architecture and the Senses. Wiley. 